\title{
Alterations of Static and Dynamic Balance in Lumbar Radiculopathy
}

\author{
MARWA A. MOHAMMAD, M.Sc.*; SOHEIR S. RIZKALLAH, Ph.D.**; MARY K. NASSIF, Ph.D.** and \\ AMR H. EL-SAYED, M.D.*** \\ The Department of Basic Sciences, Faculty of Physical Therapy, Horus* and Cairo** Universities and \\ The Department of Neurology, Faculty of Medicine, Cairo University***
}

\begin{abstract}
Background: Lumbar radiculopathy is a benign, often self-limiting condition. It is characterized by low back pain radiating into one or both lower limbs, combined with one or more positive neurological signs (paresis, sensory impairment, or loss of reflexes) that indicate a nerve root irritation or neurological loss of function. This can be due to mechanical compression of the nerve by a disc herniation which may lead to balance disorders in standing position and to asymmetrical load of lower extremities results from pain radiating to lower extremities and leads to distorted postural stability, as well as to other motor deficits. The consequences are disability, reduced quality of health and reduced working capability.
\end{abstract}

Aim of Study: The purpose of this study was to investigate the alterations of static and dynamic balance in patients with lumbar radiculopathy.

Patients and Methods: Twelve patients, both genders with unilateral lumbar radiculopathy were included in the study with a mean age $47.25( \pm 5.61)$ years. They were assessed for impairments in static and dynamic balance, compared with twelve normal/healthy subjects. functional reach test" FRT" was used to test static balance by measuring (MAD) maximum anterior reaching distance measured in $\mathrm{cm}$. and Biodex Balance System (BBS) was used to measure dynamic balance. The evaluation of dynamic balance included both Dynamic Balance Test (DBT) and the Dynamic Limits of Stability (DLOS). The (DBT) include the anterior/posterior stability index (APSI), the Medial/Lateral Stability Index (MLSI) and the Overall Stability Index (OASI). The DLOS parameters were expressed as overall Direction Control (DC) and time required for completing the test $(\mathrm{T})$.

Results: There was statistically significant differences in all measured variables of static and dynamic balance; between lumbar radiculopathy (A) and control group (B). There was a significant reduction of the mean values of OASI, APSI with $\left(p>0.0001^{*}\right)$, T with $\left(p=0.0001^{*}\right)$ and MLSI with $(p>0.002 *)$ in group (B) and significant increase of the mean values of F.R.T. in group (B). While, there was a significant increase of the mean values of D.C. with $(p=0.0001 *)$ in group (B).

Correspondence to: Dr. Marwa A. Mohammad,

The Department of Basic Sciences, Faculty of Physical Therapy, Horus University
Conclusion: There was a significant differences of all variables of static and dynamic balance between group A and $\mathrm{B}$, which confirms that patients with lumbar radiculopathy due to disc herniation may suffer impaired postural stability, dynamic balance and reduced functional abilities when compared to normal subjects.

Key Words: Lumbar Disc Herniation (LDH) - Lumbar radiculopathy - Static balance - Dynamic balance.

\section{Introduction}

LUMBAR Radiculopathy (sciatica) is a common condition that is a major cause of work absenteeism and a major financial burden to both industry and health service provision. It is a benign, often selflimiting condition which means that symptoms resolve within a matter of months. Sciatica is used to describe lumbar nerve root pain which is characterized by low back pain radiating into one or both lower limbs, combined with one or more positive neurological signs (paresis, sensory impairment, or loss of reflexes) [1].

It is caused by nerve root compression in the lumbar spine due to either disc prolapse/herniation, osteophytes or ligamentous hypertrophy. The annual incidence of low back pain is estimated at $5 \%$, but only $1 \%$ develops radiculopathy [2] .

LDH with radiculopathy can be diagnosed during clinical examination using manual muscle testing, supine straight leg raise, Lasègue sign, and crossed Lasègue sign. If a patient's history and physical examination findings indicate LDH with radiculopathy, the most suitable noninvasive test to confirm this could be an MRI [3]

Patients with low back pain and radiculopathy demonstrated some significant differences from control participants in terms of muscle activation timing, sequencing, and overall balance control. The presence of differences between patients and 
controls, specifically in the lower limb, indicates that radiculopathy may play a role in altering balance control in these patients [4]

Based on the studies that found alteration in balance in low back pain patients and as patients with lumbar radiculopathy report back pain and radiating pain in one leg, it is expected to have alterations in balance. This study was conducted to explore the change in static and dynamic balance in patients with lumbar radiculopathy.

\section{Material and Methods}

This study was conducted in the balance laboratory at Faculty of Physical Therapy, Cairo University, in the period from July to October 2017. The aim of this study was to investigate the alterations of static and dynamic balance in patients with lumbar radiculopathy.

\section{Pilot study:}

Pilot study was conducted on eight participants, four patients with lumbar radiculopathy and four normal subjects. Static balance was assessed by the FRT, while dynamic balance was assessed by Biodex Balance System using dynamic balance test at stability level (5) and dynamic limits of stability test at stability level (7). Statistical analysis using MANOVA revealed high significance difference in values of MAD, OASI, APSI, MLSI, DC $\& \mathrm{~T}$ between the two groups.

\section{Sample size:}

The sample size calculations were performed using the $\mathrm{G}^{*}$ Power software (Version 3.0.10). Ftest MANOVA with global effects was selected. It was calculated from a pilot study on 16 participants in two groups, 8 with lumbar radiculopathy and 8 without radiculopathy. Partial eta square effect size of the overall dependent variable was calculated $\left(\mathrm{f}^{2}(\mathrm{~V})=8\right)$. Considering a power of 0.95 , an $\alpha$ level of $0.05,2$ groups and response variables of 6 , a generated sample size of at least 24 participants per group would be required. Allowing for a $20 \%$ dropout rate, it was necessary to reach a total sample level of a minimum of 50 participants.

\section{Subjects:}

Twenty fourparticipants ( 12 females and 12 males) of both sexes were selected for this study from the outpatient clinic in the Faculty of Physiotherapy, Cairo University.

They were assigned into two equal groups. Group (A) or lumbar radiculopathy group consisted of 12 participants with mean age (which ranged from 35 to 55 years), body mass, height, and BMI (which ranged from 18.5 up to $<30 \mathrm{Kg} / \mathrm{m}^{2}$ ) values of $47.25 \pm 5.61$ years, $73.58 \pm 5.29 \mathrm{~kg}, 166.75 \pm 4.47$ $\mathrm{cm}$, and $26.44 \pm 2.27 \mathrm{Kg} / \mathrm{m}^{2}$ respectively. Group (B) or control group consisted of 12 participants with mean age (which ranged from 35 to 55 years), body mass, height, and BMI (which ranged from 18.5 up to $<30 \mathrm{Kg} / \mathrm{m}^{2}$ ) values of $41.41 \pm 6.8$ years, $74.5 \pm 12.3 \mathrm{~kg}, 168.41 \pm 8.06 \mathrm{~cm}$, and $26.13 \pm 3.65$ $\mathrm{Kg} / \mathrm{m}$ respectively. All subjects were chosen by their willingness to participate and assessment was conducted only for one time.

Primary outcome measures were (MAD) maximum anterior reaching distance measured in $\mathrm{cm}$. for static balance and Overall Stability Index (OASI), Anterior/Posterior Stability index (APSI), Medial/Lateral Stability Index (MLSI), over all Directional Control (D.C.) value and Total test time $(\mathrm{T})$.

\section{Inclusion criteria:}

Twenty four male and female patients participated in this study based on the following inclusion criteria:

Patient with BMI ranged from 18.5 up to $<30$ $\mathrm{Kg} / \mathrm{m}^{2}$ diagnosed as L4-5 and/or L5-S1 disc herniation with sciatica. Duration of illness lasted more than 3 months. Age of patients ranged from 35 to 55 years. All patients had positive SLR (straight leg raising). Severity of suffered sciatic pain was mild to moderate expressed from (3 to 6) at Numerical Pain Rating Scale (NPRS).

\section{Exclusion criteria:}

Patients with previous surgery in the lumbar spine, fractures in the lumbar and sacral spine, patients with neoplastic conditions, vascular compromise, pregnant women, patients with history of cerebral concussions, visual acuity impairment, orthopedic or vestibular disorders, patients with any neurological deficit affecting balance e.g. parkinsonism and diabetic patients were excluded from the study.

Study design: The study is a one shot cross sectional study. After selection of the patients an informed consent was taken from all patients that participated in the study and they were informed about the aims, benefits and procedure of the study. The study was implemented and approved under the supervision of the ethical committee, Faculty of Physical Therapy, Cairo University with number P.T.REC/012/001522. This study is registered in the Pan African Clinical Trial Registry (PACTR) under the number (PACTR201707002022222). All subjects were chosen by their willingness to participate. 


\section{Evaluation:}

- Pain assessment: Assessment was done by using NPRS, the patient was giving a blank paper with a line of $10 \mathrm{~cm}$. Marked on it this line is divided from 0 to 10 . The patient was instructed that 0 means no pain and 10 means killing pain. The patient was instructed to select number on that line that corresponds to the current pain intensity in the back and leg [5] .

\section{- Static balance assessment:}

Directions for Functional Reach Test (FRT): With the subject standing close to a yardstick mounted on the wall at shoulder height they were asked to flex there arm to $90^{\circ}$ and fist their hand. The starting position was determined by which MCP joints lined up on the yardstick. The subject was then instructed to reach as far forward as possible in a plane parallel with the measuring device. The end position was then documented and the difference between standing and ending position was considered (MAD).

Instructions: Reach as far forward as you can without taking a step, keeping your feet flat on the floor, and keeping your hand at the level of the ruler."

A Score less than 6 or 7 inches indicated limited functional balance [6]

Criteria to stop the test: The patient's feet lifted up from the floor or they fell forward. Most patients fall forward with this test. The therapist should guard from the front as that is the direction that you reach forward.

- Dynamic balance assessment: The first procedure was Dynamic Balance Test (DBT) which measures (OASI, APSI and MLSI). The eyes were opened, the test duration was 20 seconds with stability level 5 (moderate level) [7] and constant all over the test duration. The subjects in all groups were instructed to stand barefoot and to assume proper centered position as soon as the platform was released. The feet positions were recorded by using foot angles and coordinates on the platform grid. When the task time ended the OASI, APSI and MLSI were recorded automatically.

The second procedure was DLOS testwhich measures motor control skills (DC and T) with stability level 7 [8]. Once the test started the subjects tried to move the cursor to the box which appeared on the screen with little deviation as possible. When the test was completed, the DC and T were recorded automatically. During the actual tests, every subject was instructed to assume the same foot position in both procedures. A pause of 2 minutes was taken between the two procedures to minimize errors from adaptation.

\section{Results}

The main purpose of this study was to investigate the alterations of static and dynamic balance in lumbar radiculopathy.

Statistical analysis was conducted using SPSS for windows, Version 22 (SPSS, Inc., Chicago, IL). The current test involved one independent variable, it was the (tested groups); between subject factor which had two levels (group A represents lumbar radiculopathy or study group) and (group $\mathrm{B}$ represents healthy or control group). In addition, this test involved six tested dependent variables (static balance (maximum anterior distance MAD), dynamic balance (OASI, APSI, and MLSI), and D.L.O.S (Over all directional control (D.C.) and Total test time "T")).

Prior to final analysis, data were screened for normality assumption, homogeneity of variance, and presence of extreme scores. This exploration was done as a pre-requisite for parametric calculations of the analysis of difference.

Descriptive analysis using histograms with the normal distribution curve showed that the MAD, OASI, APSI, and MLSI, D.C., and "T" were normally distributed and didn't violate the parametric assumption for the measured dependent variable. Additionally, testing for the homogeneity of covariance revealed that there was no significant difference with $p$-values of $>0.05$. The box and whiskers plots of the tested variable were carried out to detect the outliers and showed no outliers. Normality test of data using Shapiro-Wilk test was used, that reflected the data was normally distributed for all dependent variables. Between subject comparison MANOVA was used to compare all these variables between both groups with the alpha level 0.05 .

\section{General characteristics:}

The current study was conducted on 24 participants ( 12 females and 12 males). They were assigned into two equal groups. Group (A) consisted of 12 participants with mean age, body mass, height, and BMI values of $47.25 \pm 5.61$ years, $73.58 \pm$ $5.29 \mathrm{~kg}, 166.75 \pm 4.47 \mathrm{~cm}$, and $26.44 \pm 2.27 \mathrm{Kg} / \mathrm{m}^{2}$ respectively. Group (B) consisted of 12 participants with mean age, body mass, height, and BMI values of $41.41 \pm 6.8$ years, $74.5 \pm 12.3 \mathrm{~kg}, 168.41 \pm 8.06 \mathrm{~cm}$, and $26.13 \pm 3.65 \mathrm{Kg} / \mathrm{m}^{2}$ respectively. As indicated 
by the independent $t$ test, there were no significant differences $(p>0.05)$ in the mean values of age, body mass, and height between both tested groups (Table 1). The sex distribution of group A revealed that there were 7 females with reported percentage of $58.3 \%$ and 5 males with reported percentage of $41.7 \%$. The sex distribution of group B revealed that there were 5 females with reported percentage of $41.7 \%$ and 7 males with reported percentage of $58.3 \%$. as shown in (Table 1). Chi square revealed there was no significant differences between both groups in sex distribution $(p>0.05)$.

Table (1): Physical characteristics of participants in both groups (A \& B).

\begin{tabular}{|c|c|c|c|c|c|}
\hline \multirow{2}{*}{ Items } & \multirow{2}{*}{$\begin{array}{c}\text { Group A } \\
\text { Mean } \pm \text { SD }\end{array}$} & \multirow{2}{*}{$\begin{array}{c}\text { Group B } \\
\text { Mean } \pm \text { SD }\end{array}$} & \multicolumn{2}{|c|}{ Comparison } & \multirow{2}{*}{ S } \\
\hline & & & $t$-value & $p$-value & \\
\hline Age (years) & $47.25 \pm 5.61$ & $41.41 \pm 6.8$ & 2.292 & 0.05 & NS \\
\hline Body mass (Kg) & $73.58 \pm 5.29$ & $74.5 \pm 12.3$ & -0.237 & 0.815 & NS \\
\hline Height $(\mathrm{cm})$ & $166.75 \pm 4.47$ & $168.41 \pm 8.06$ & -0.626 & 0.538 & NS \\
\hline BMI $\left(\mathrm{kg} / \mathrm{m}^{2}\right)$ & $26.44 \pm 2.27$ & $26.13 \pm 3.65$ & 0.248 & 0.806 & NS \\
\hline $\begin{array}{l}\text { Sex distribution } \\
\text { N }(\%)\end{array}$ & Group A & Group B & $x^{2}$ & $p$-value & NS \\
\hline Female & $7(53.8 \%)$ & $5(41.7 \%)$ & 0.667 & .684 & NS \\
\hline Male & $5(41.7 \%)$ & $7(58.3 \%)$ & & & \\
\hline
\end{tabular}

One way MANOVA for dependent variables between both groups:

Statistical analysis using one way MANOVA indicated that there were significant effects of the tested conditions (the independent variable) on the six tested dependent variables; the MAD, OASI, APSI, and MLSI, D.C., and T $(\mathrm{F}=22.059, p=$ $0.0001 *)$.

\section{Multiple pairwise comparison tests (post hoc tests):}

1- Static balance (MAD): As presented in (Table 2 ), between group's comparison the mean $\pm \mathrm{SD}$ values of MAD in the group $\mathrm{A}$ and the group $\mathrm{B}$ were $16.91 \pm 4.54$ and $37.25 \pm 4.28$ respectively. The univariate tests revealed that there were significant differences in the mean values of the "MAD" between both groups with $(\mathrm{F}=127.164$, $p>0.0001 *)$. So, multiple pairwise comparison tests (post hoc tests) revealed that the mean values of the MAD between both groups showed significant differences with $(p>0.0001 *)$ and this significant reduction in favor to group A.

\section{2- Dynamic balance:}

\section{1- Dynamic Balance Test (DBT):}

A- OASI: As presented in (Table 3), between group's comparison the mean \pm SD values of OASI in the group A and the group B were $5.15 \pm 2.2$ and $1.64 \pm 0.66$ respectively. The univariate tests revealed that there were significant differences in the mean values of the "OASI" between both groups with $(\mathrm{F}=27.849, p>0.0001)$. So, multiple pairwise comparison tests (Post hoc tests) revealed that the mean values of the OASI between both groups showed significant differences with $\left(p>0.0001^{*}\right)$ and this significant reduction in favor to group B.

Table (2): Descriptive statistics and one-way Multivariate Analysis of Variance (MANOVA) for the static balance (MAD) between both groups.

\begin{tabular}{|c|c|c|}
\hline Static balance & $\begin{array}{l}\text { Group A } \\
\text { Mean } \pm \text { SD }\end{array}$ & $\begin{array}{c}\text { Group B } \\
\text { Mean } \pm \text { SD }\end{array}$ \\
\hline MAD & $16.91 \pm 4.54$ & $37.25 \pm 4.28$ \\
\hline \multicolumn{3}{|c|}{ The univariate tests for the mean of the MAD between both groups } \\
\hline & F-value & $p$-value \\
\hline MAD & 127.164 & $<0.0001 *$ \\
\hline \multicolumn{3}{|c|}{$\begin{array}{l}\text { Multiple pairwise comparison tests (post hoc tests) for the MAD } \\
\text { between both groups }\end{array}$} \\
\hline MAD & Group A vs. Group B & $p>0.0001 *$ \\
\hline
\end{tabular}

$B$ - APSI: As presented in (Table 3), between group's comparison, the mean \pm SD values of APSI in the group A and the group B were 4.28 \pm 1.88 and $1.38 \pm 0.49$ respectively. The univariate tests revealed that there were significant differences in the mean values of the "APSI" between both groups with $(\mathrm{F}=26.461, p>0.0001)$. So, multiple pairwise comparison tests (post hoc tests) revealed that the mean values of the APSI between both groups showed significant differences with $\left(p>0.0001^{*}\right)$ and this significant reduction in favor to group B.

$C$ - MLSI: As presented in (Table 3), between group's comparison, the mean \pm SD values of MLSI in the group A and the group B were $2.85 \pm 1.66$ and $1.05 \pm 0.57$ respectively. The univariate tests revealed that there were significant differences in the mean values of the "MLSI" between both groups with $\left(\mathrm{F}=12.476, p>0.002^{*}\right)$. So, multiple pairwise comparison tests (post hoc tests) revealed that the mean values of the MLSI between both groups showed significant differences with $\left(p>0.002^{*}\right)$ and this significant reduction in favor to group B.

\section{2- Dynamic Limits of Stability (D.L.O.S.):}

A- Overall directional control (D.C.): As presented in (Table 4), between group's comparison, the mean \pm SD values of overall Directional Control (D.C.) in the group A and the group B were $22 \pm$ 11.34 and $50.75 \pm 17.5$ respectively. The univariate tests revealed that there were significant differences 
in the mean values of the "over all Directional Control (D.C.)" between both groups with $(\mathrm{F}=$ $22.796, p=0.0001 *)$. So, multiple pairwise comparison tests (post hoc tests) revealed that the mean values of the overall Directional Control (D.C.) between both groups showed significant differences with $(p=0.0001 *)$ and this significant increase in favor to group B.

Table (3): Descriptive statistics and one-way Multivariate Analysis of Variance (MANOVA) for the dynamic balance (OASI, APSI, and MLSI) between both groups.

\begin{tabular}{lcc}
\hline Dynamic balance & $\begin{array}{c}\text { Group A } \\
\text { Mean } \pm \text { SD }\end{array}$ & $\begin{array}{c}\text { Group B } \\
\text { Mean } \pm \text { SD }\end{array}$ \\
\hline OASI & $5.15 \pm 2.2$ & $1.64 \pm 0.66$ \\
APSI & $4.28 \pm 1.88$ & $1.38 \pm 0.49$ \\
MLSI & $2.85 \pm 1.66$ & $1.05 \pm 0.57$ \\
\hline
\end{tabular}

The univariate tests for the mean of the dynamic balance (OSI, A/P, and $\mathrm{M} / \mathrm{L}$ ) between both groups

\begin{tabular}{lcc}
\hline Dynamic balance & F-value & $p$-value \\
\hline OASI & 27.849 & $>0.0001^{*}$ \\
APSI & 26.461 & $>0.0001^{*}$ \\
MLSI & 12.476 & $>0.002^{*}$ \\
\hline
\end{tabular}

Multiple pairwise comparison tests (post hoc tests) for the dynamic balance (OASI, APSI, and MLSI) between both groups

\begin{tabular}{lccc}
\hline Group A vs. Group B & OASI & APSI & MLSI \\
\hline$p$-value & $>0.0001^{*}$ & $>0.0001^{*}$ & $>0.002 *$ \\
\hline
\end{tabular}

*: Significant at alpha level $<0.05$.

Table (4): Descriptive statistics and one-way Multivariate Analysis of Variance (MANOVA) for the D.L.O.S (over all directional control and total test time) between both groups.

\begin{tabular}{lcc}
\hline D.L.O.S & $\begin{array}{c}\text { Group A } \\
\text { Mean } \pm \text { SD }\end{array}$ & $\begin{array}{c}\text { Group B } \\
\text { Mean } \pm \text { SD }\end{array}$ \\
\hline Overall directional control (D.C.) & $22 \pm 11.34$ & $50.75 \pm 17.5$ \\
Total test time (T) & $2.79 \pm 1.2$ & $1.25 \pm 0.28$ \\
\hline
\end{tabular}

The univariate tests for the mean of the D.L.O.S (over all directional control and total test time) between both groups

\begin{tabular}{lcc}
\hline D.L.O.S & F-value & $p$-value \\
\hline Overall directional control (D.C.) & 22.796 & $0.0001^{*}$ \\
Total test time (T) & 17.754 & $0.0001^{*}$ \\
\hline
\end{tabular}

Multiple pairwise comparison tests (post hoc tests) for the D.L.O.S (over all directional control and total test time) between both groups

\begin{tabular}{lcc}
\hline Group A vs. Group B & Overall directional control & Total test time \\
\hline$p$-value & $0.0001^{*}$ & $0.0001^{*}$ \\
\hline
\end{tabular}

*: Significant at alpha level $<0.05$.

B- Total test time (T): As presented in (Table 4 ), between group's comparison, the mean \pm SD values of total test time in the group $A$ and the group B were $2.79 \pm 1.2$ and $1.25 \pm 0.28$ respectively. The univariate tests revealed that there were significant differences in the mean values of the "total test time" between both groups with $(\mathrm{F}=17.754$, $p=0.0001 *)$. So, multiple pairwise comparison tests (post hoc tests) revealed that the mean values of the total test time between both groups showed significant differences with $(p=0.0001 *)$ and this significant reduction in favor to group B.

\section{Discussion}

Radiculopathy may be from direct trauma or from chemical irritation to the affected nerve root. This can be due to mechanical compression of the nerve by a disc herniation, or from thickening of surrounding ligaments. As individuals age, their spines are subject to increasing degeneration which can cause herniated discs and similar problems, leading to lumbar radiculopathy Kennedy et al., [9] and Iversen T. et al., [10]

In the present study we found significant differences in the mean values for "MAD" between both groups, where LR group scored lower values than that of normal individuals indicating limited static balance.

Our results comes in line with Truszczyńska A. et al., [11]; where theyfound that patients with intervertebral disc disease had a lower mean frequency of COP sways than the clinical control group. They suggested that increased tension and muscle stiffness in patients with back pain anddecreased mobility of the spine as well as by changes to the muscle activation, a strategy that limits mobility of the spine even further and affect negatively on static functional abilities as reaching forward activities.

Additionally our results came into accordance with Thakkar HH. et al., [12] where they found that chronic low back pain increased the postural sway in quiet stance due to reduction of the function and coordination of stabilization of low back muscle. They suggested that reduction of postural stability and neuromuscular control aided in varied postural sway among CLBP group. Moreover there were changes in proprioception transmission, paraspinal muscle spindle dysfunction, and delay in muscle recruitment along with poor postural control.

One explanation for the decreased MAD found in LR in our study is that there (normal standing posture may increase muscle activation of back muscles, which will may result in an increased fatigue rate. Additionally, pain extending down the leg may directly affect quiet standing control. 
The current study is agreed with results of Kuai S. et al., [13] who concluded that LDH patients displayed more muscle activities, larger intradiscal forces, and more facet interventions during trunk flexion and two types of picking up. These changes might be a compensatory response to relieve pain and improve spinal stability. However, these responses further burdened the trunk musculature, passive soft tissue, and spinal structure during functional tasks e.g. forward reaching tested in our study. In addition to that findings, he concluded that the compensatory response of kinetics in LDH patients played a rather negative role in maintaining the spinal stability and further led to the development of disc herniation.

Contrasting to our results Paalanne, Niko [14] demonstrated that there was no significant differences in body sway in standing position between healthy adults and patients with non-specific LBP. Contrasting results might be partly explained by using different methods in assessing body sway. Where direct inclinometric methods or force platforms, were used to record ground reaction forces where body sway is calculated indirectly. Another explanation between this and previous studies is the age of the subjects. Our study was conducted by subjects within the range of older adult populations and its results came into contrary to Paalanne, Niko who reported that body sway did not increase in LBP patients compared to healthy in a study conducted on young adults (mean age 22.7 years) controls. That findings was strongly supported by Fujita et al., [15] who stated that body sway increases with age.

With regards to dynamic balance, we found a significant difference between both groups in terms of "OSI, "APSI", "MLSI", “DLOS", "D.C.” and "T" where LR group scored higher postural sway during dynamic balance.

Additionally, LR group scored lower values in DC and higher values in total test time (T) than that of normal individuals indicating that LR individuals needed more time to complete the test and had poor DC when carrying out the test.

Additionally Thakkar HH. et al., [12] found that excursion distances was reduced in CLBP group due to deficits in proprioception and tactile acuity.

One explanation may be that balance dysfunctions are attributed by altered feedback input from lumbar spine. In addition to it; pain proprioception inhibits the recruitment of muscular pattern from lumbar to ankle joint, CLBP also exhibits faulty kinematics aiding in poor performance. The find- ings of our study regarding OSI and MLSI are consistent with Karimi N. et al., [16] thatshoweda significant difference in the OSI and MLSI between healthy group and LBP due to hip abductor weakness and imbalance in patients with LBP.

Ciesielska J. et al., [17] founds EMG fluctuations between healthy and LDH groups. The amount of the fluctuations was lower in patients with LDH than that in the healthy subjects. There were significant differences in the gluteus maximus muscle as well as in the rectus femoris in both limbs, although there were greater differences on the dysfunctional side and usually for the rectus femoris muscle. Statistically significant differences were observed in the Eyes Open (EO) and Eyes Closed (EC) positions which interprets our results regarding significant differences in APSI and increasing body sway in this direction between groups.

In contrast to the our study Jacobs et al., [18] \& Jones et al., [19] found that in almost all of the positions tested, the values that characterized the average velocities of Center of Pressure (COP) displacements in both directions (AP, L) which measured in quit standing on the balance platform in the LBP patients were similar to those achieved by the healthy subjects and there was no significant difference in that directions and he explained this findings as patients with LBP exhibit postural responses that are dominated by movements around the ankle rather than the hip. Decreased participation of the hip joint may be a strategy employed to minimize forces and movement about the trunk, which is aimed at avoiding pain.

Our study results are strongly interpreted by primary finding of Frost et al., [20] whofound that, in response to whole body balance perturbations, LBP-R patients demonstrated some delays in medial gastrocnemius MG and tibialis anterior TA activation as well as evidence of altered muscle sequencing in comparison matched healthy controls. This may have contributed to that the nerve conduction velocity decreases in chronic nerve compression pathologies. In a concurrent investigation on the same patient population as presented here, greater sciatic nerve Cross Sectional Area (CSA) was found in the affected leg of the LBP-R patient population which has a great impact on both static and dynamic balance.

Our findings regarding impaired dynamic postural stability are in agreement with Truszczy nska A. et al., [11] who observed in the field of COP (SA) that there were significant differences between the LDH patients and the clinical control group, 
in measurements with eyes open. The reason for a larger field of COP may be the limited ability to use hip joint strategies to maintain balance. In addition, patients with back pain tend to reveal strategies of the ankle joint to maintain balance.

The asymmetry in foot pressure may result from radiating pain and from proprioception disorder. Drzal-Grabiec J. et al., [21] . This may be explained by torso transposition found in patients with lumbar Intervertebral Disc Disease (IVDD) prior to surgery Sipko et al., [22] . This transposition of the torso led to asymmetry of foot pressure on the painful side. Additionally, post surgery, when pain was less, postural control was improved.

In summary, LR patients suffered both static and dynamic balance deficits as when compared to normal individuals.

\section{Limitations:}

A lot of effort was exerted with each subject to reduce the influence of the possible errors inherent in this study. The limitation of this study was:

- Small sample size.

\section{Conclusion:}

There was a significant difference of all variables of static and dynamic balance between group $\mathrm{A}$ and $\mathrm{B}$, which confirms that patients with lumbar radiculopathy due to disc herniation may suffer impaired postural stability, dynamic balance and reduced functional abilities when compared to normals.

\section{Acknowledgements:}

The authors would like to express appreciation to all subjects who participated in this study and to colleagues at the out-patient clinic, Faculty of Physical Therapy, Cairo University, Giza, Egypt.

\section{References}

1- M.A. STAFFORD, P. PENG and D.A. HILL: Sciatica: A review of history, epidemiology, pathogenesis, and the role of epidural steroid injection in management, BJA. British Journal of Anaesthesia, Volume 99, Issue 4, Pages 461-73, 2007.

2- OMAR E.A., PIMENTEL D.C. and AMADERA J.E.D.: Chapter 15-spinal pathology: Nonsurgical intervention a2-magee, david j. In J.E. Zachazewski, W.S. Quillen and R.C. Manske (Eds.), Pathology and intervention in musculoskeletal rehabilitation (second edition), (pp. 561-83): W.B. Saunders, 2016.

3- MASSIMO ALLEGRI A.1,2; SILVANA MONTELLA1; FABIANA SALICI1; ADRIANA VALENTE2; MAURIZIO MARCHESINI2; CHRISTIAN COMPAGNONE2; MARCO BACIARELLO1,2; MARIA ELENA MANFER-
DINI2 and GUIDO FANELLI: Mechanisms of low back pain: A guide for diagnosis and therapy Version 2. F1000Res., 5: F1000 Faculty Rev-1530, 2016.

4- LYDIA R. FROST and STEPHEN H.M.: Muscle activation timing and balance response in chronic lower back pain patients with associated radiculopathy. Brown, Volume 32, Pages 124-30, 2016.

5- KREBS E., CAREY T. and WEINBERG M.: Accuracy of pain numeric rating scale as a screening test in primary care. Journal of General Internal Medicine, 22: 1453-8, 2007.

6- PÉRICLES A. MARANHÃO-FILHO,ELIANA TEIXEIRA MARANHÃO, MARCOS MARTINS Da SILVA and MARCO ANTÔNIO LIMA: Rethinking the neurological examination IStatic balance assessment. Arq. Neuropsiquiatr., 69 (6): 954-8, 2011.

7- SHIVA SHERAFAT, et al.: Intrasession and intersession reliability of postural control in participants with and without nonspecific low back pain using the biodex balance system. J. Manipulative Physiol. Ther., 36: 1118) Volume 36, Number 2, 2013

8- PUGH, STEVEN F., et al.: Effects of augmented visual feedback and stability level on standing balance performance using the Biodex Balance System. The Sport Journal, Vol. 14, No. 1., 2011.

9- KENNEDY D.J., et al.: The role of core stabilization in lumbosacral radiculopathy. Phys. Med. Rehabil. Clin. N. Am., Feb. 2011.

10- TROND IVERSEN, et al.: Accuracy of pradiculopathy. BMC musculoskeletal disorders, 14: 206, 2013.

11- ALEKŞANDRA TRUSZCZYNSKA, MARTYNA DOBRZYNSKA, ZBIGNIEW TRZASKOMA, JUSTYNA DRZAL-GRABIEC and ADAM TARNOWSK: Assessment of postural stability in patients with lumbar spine chronic disc disease. Acta of Bioengineering and Biomechanics, Vol. 18, No. 4, 2016.

12- THAKKAR H.H. and SENTHIL KUMAR E.: Static and dynamic postural stability in subjects with and without chronic low back pain. Int. J. Res. Med. Sci., 3: 2405-9, 2015.

13- SHENGZHENG KUAI, WEIQIANG LIU, RUN JI and WENYU ZHOU: The Effect of Lumbar Disc Herniation on Spine Loading Characteristics during Trunk Flexion and Two Types of Picking Up Activities. Hindawi.

14- Postural Balance, Isometric Trunk Muscle StrengthH and Low Back Symptoms Among Young Adults, ISSN 03553221, Niko Paalanne, Oulun yliopisto, University of Oulu, 9514294998, 9789514294990, 2011.

15- FUJITA T., NAKAMURA S., et al.: Effect of age on body sway assessed by computerized posturography. Journal of Bone and Mineral Metabolism, 23 (2): 152-6, 2005.

16- KARIMI N., EBRAHIMI I., KAHRIZI S. and TORKAMAN G.: Evaluation of postural balance using the biodex balance system in subjects with and without low back pain. Pak. J. Med. Sci., 24 (3): 372-7, 2008.

17- JAGODA CIESIELSKA, PRZEMYSLAW LISINSKI, AGATA BANDOSZ, JULIUSZ HUBER and ALEKSANDRA KULCZYK: Hip strategy alterations in patients with history of low disc herniation and non-specific low back pain measured by surface electromyography and 
balance platform. Acta Bioeng. Biomech., 17 (3): 103-8, 2017.

18- JACOBS J.V., HENRY S.M., JONES S.L., HITT J.R. and BUNN J.Y.: A history of low back pain associates with altered electromyographic activation patterns in response to perturbations of standing balance. J. Neurophysiol., Vol. 106 (5): 2506-14, 2011.

19- JONES S.L., HITT J.R., DESARNO M.J. and HENRY S.M.: Individuals with non-specific low back pain in an active episode demonstrate temporally altered torque responses and direction-specific enhanced muscle activity following unexpected balance perturbations, Exp. Brain Res., Vol. 221 (4): 413-26, 2012.

20- FROST R.L., BIJMAN M., STRZALKOWSKI N.D.J.,
BENT L.R. and BROWN S.H.M.: Deficits in foot skin sensation are related to alterations in balance control in chronic low back patients experiencing clinical signs of lumbar nerve root impingement. Gait Posture, 41 (4): 923-8, 2015.

21- DRZAL-GRABIEC J., et al.: Effects of carrying a backpack in an asymmetrical manner on the asymmetries of the trunk and parameters defining lateral flexion of the spine. Hum Factors, Mar., 57 (2): 218-26, 2015.

22- SIPKO T., CHANTSOULIS-SUPINSKA M.,ZMUDA M. and ZWOLINSKI J.: Postural balance in the early post-operative period in patients with intervertebral disk disease following surgery. Ortop. Traumatol. Rehabil., 10 (3): 226-47, 2008.

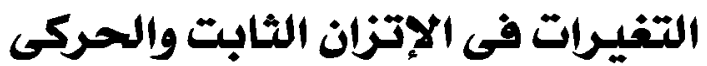 \\ للدى مرضى إمتّلال الجذان الجذابت والقطنية
}

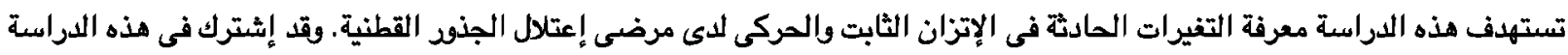

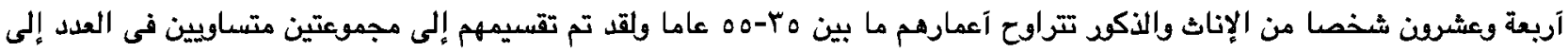

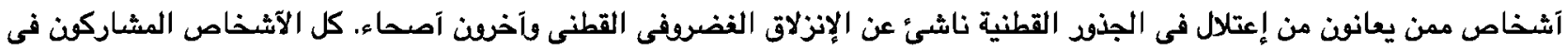

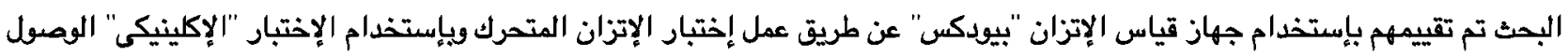

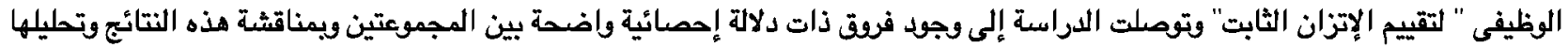

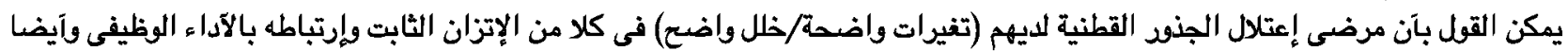

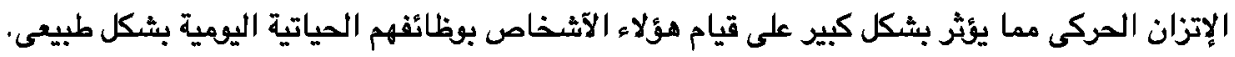

